\title{
Characterization and Optimization of the Steel Beam to RC Wall Connection for use in Innovative Hybrid Coupled Wall Systems
}

\author{
R. Das ${ }^{a *}$, H. Degee ${ }^{a}$ \\ ${ }^{a}$ Construction Engineering Research Group, Hasselt University, Hasselt, Belgium \\ *corresponding author, e-mail address: rajarshi.das@uhasselt.be
}

\begin{abstract}
Replaceable fuses as coupling elements, with detailed composite connections, can state the steel and concrete hybrid structures to be one of the best alternatives for a more feasible and easy repairable earthquake-proof structure. Therefore, an efficient composite connection for a newly suggested Hybrid Coupled Wall (HCW) system, consisting of a reinforced concrete shear wall coupled with steel side columns via dissipative steel shear links, is studied in this paper. The steel shear links are connected to a steel profile, embedded or passing through the RC wall. This embedded part should be so designed that the damage always occurs on the steel shear links (fuses) prior to minimal damage in the $\mathrm{RC}$ wall and embedded connection. The emphasis is on characterizing a suitable "steel link + embedded composite connection within the RC wall" configuration and calculate an appropriate embedment length while concentrating the seismic damage to the replaceable steel links. To this purpose, two joint configurations are designed through a capacity based approach, namely "partly embedded" and "passing through" steel beam connection and are examined through detailed FE analyses. A parametric study was also carried out to provide sufficient evidence towards the design considerations proposed in this study, in terms of strength, stiffness and bearing strength within the embedded connection.
\end{abstract}

Keywords: Steel and concrete hybrid connections; Embedment length; Energy dissipation; Seismic-resistant structures; Embedded steel sections.

\section{Introduction}

Reinforced concrete (RC) walls coupled by $\mathrm{RC}$ beams [1, 2] to more recent steel and concrete hybrid coupled walls (HCWs) with steel or composite beams as structural fuses [3, 4], has provided an efficient solution towards earthquake resistant structures. To further improve the combination of the RC wall and steel elements, a new structural configuration for HCW systems was recently proposed, developed and studied using numerical and experimental tools in the European research project INNOHYCO (INNOvative HYbrid and COmposite steel-concrete structural solutions for building in seismic area, [5]). This system consists of a RC shear wall coupled to steel side columns by means of steel links. The RC wall carries almost all the horizontal shear force while the overturning moments are partially resisted by an axial compression-tension couple developed by the two side steel columns rather than by the individual flexural action of the wall alone.

To exploit the full potential of the proposed HCW system and allow for an easy replacement effort, the steel coupling links should be designed as replaceable fuses and the connection should also fulfil the same purpose. So, to achieve the foretold performance objective, the primary steel links are connected either to an embedded steel beam or a beam passing through the RC wall and the embedded connection should be so designed that the seismic damage is always concentrated in the replaceable primary steel links which act as fuse elements, i.e. intended to fail before any or minimal damage in the RC wall as well as other components of the connection. Although, previous studies by various researches [6-10]; have investigated the behaviour of such embedded connections, a certain simple and refined design procedure is 
necessary to further optimize the embedded length. Therefore, the primary objective of this investigation is to develop such a design procedure based on a refined characterization of the connection performance, embedded within the RC wall, to calculate an optimized embedment length for such HCW structures. Therefore, two types of joint configurations are investigated in this research work, on the basis of a capacity based design approach and a detailed parametric analysis; 1) Partially embedded (Fig. 1a); 2) Passing through (Fig. 2a) steel beam connection. In both connection configurations, the bending moment transferred by the link to the wall is balanced by a couple of vertical bearing forces at the steel concrete interface as shown in Fig. $1 b$ and $2 b$. The parametric study, with FE models, primarily focuses upon the vertical stress distributions of the concrete through the embedded profile for different embedment lengths to verify the prime considerations of the design method.

(a)

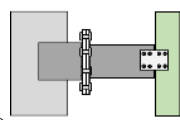

(b)

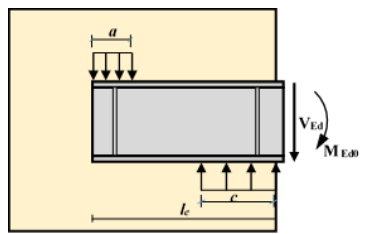

Fig. 1. Configuration 1: (a) Schematic diagram (b) resistance mechanism.

(a)

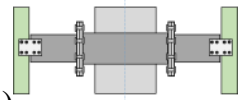

(b)

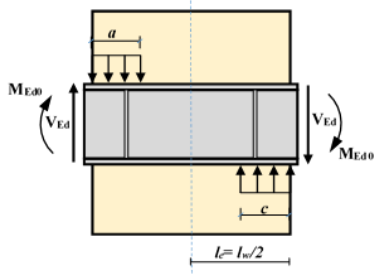

Fig. 2. Configuration 2: (a) Schematic diagram

(b) resistance mechanism.

Lack of detailed evidence about such connections with the foretold design objectives has encouraged this investigation. The aim of this research is to find a suitable steel-composite embedded connection as well as an associated design procedure, to be applied for the newly proposed INNO-HYCO HCW systems [5] to accommodate the replaceable links and verify the anticipated seismic behaviour. This goal is attained by a proposed capacity based design procedure described in the later section of this article. The parametric study also provides enough evidence for the development of the proposed design procedure.

\section{Design Methodology}

Although the design procedure followed for this investigation is globally similar for both connection configurations, the equilibrium equations change slightly in Step 3. Steps 1, 2, 4, and 5 remain the same for both. This procedure is essentially a continuation of the global design methodology proposed in the earlier studies [11] and focuses specifically on the embedded connection aspects.

Step 1: Design of the $R C$ wall and steel link (fuse): The dimensions and reinforcement details of the RC wall, steel columns and steel shear links are calculated according to a recently proposed design procedure [11] used for global characterization of innovative HCW structures.

Step 2: Design loads on the embedded profile: According to the link-to-wall force transfer mechanism, the embedded profile is designed assuming a linear increase of bending moment until the location of the first reaction force applied by the concrete on the profile. Suitable overstrength factors are chosen. Values at three different locations: i) the beam splice connection, ii) face of the RC wall, iii) location of the first reaction applied by the concrete (taken as $1 / 3$ rd of the embedment length as recommended by previous researches [6-9]); are first increased by the overstrength factors and are used to design the embedded profile. The overstrength factors and design load formulas corresponding to shear critical links are given below for clarity. The overstrength factors considered for the design are:

$\gamma_{o v}=1.25, \gamma_{M 0}=1.00, \gamma_{M 1}=1.00, \gamma_{M 2}=1.25$,

$\gamma_{c}=1.50, \gamma_{s}=1.50, \Omega=1.5$

As shear links are chosen in the previous design study, calculations start from $V_{p, \text { link, }}$ (plastic shear capacity of the link); as shown below. Expressions for $V_{p, \text { link }}$ are obtained from Eurocode 8 [12]. The following design loads in Eq. (1-4) are calculated according to Fig. 3:

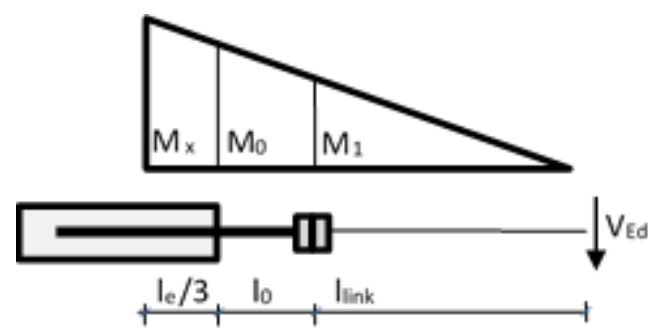

Fig. 3. Static scheme to calculate design loads 


$$
\begin{aligned}
& V_{0}=V_{p, \text { link }}=\frac{f_{y}}{\sqrt{3}} t_{w}\left(d-t_{f}\right) ; V_{E d}=1.1 V_{0} \Omega \\
& M_{1}=V_{0} l_{\text {link }} ; M_{E d 1}=1.1 M_{1} \gamma_{o v} \Omega \\
& M_{0}=M_{1} \frac{l_{\text {link }}+l_{0}}{l_{\text {link }}} ; M_{E d 0}=1.1 M_{0} \gamma_{o v} \Omega \\
& M_{x}=M_{1} \frac{l_{\text {link }}+l_{0}+\frac{l_{e}}{3}}{l_{\text {link }}} ; M_{E d x}=1.1 M_{x} \gamma_{o v} \Omega
\end{aligned}
$$

where $f_{y}$ is the nominal yield stress; $d$ is the total depth of the section; $b$ is the flange width; $t_{f}$ is the flange thickness, $t_{w}$ is the web thickness, $l_{\text {link }}$ is the link length (from the face of column to the center of the beam splice connection). $l_{0}$ is the offset length of the beam splice, $l_{e}$ is the embedment length. $M_{1}, M_{0}$, and $M_{x}$ are the moments at the beam splice connection, the face of the wall and location of the first reaction force applied by the concrete on the profile respectively. Finally, $V_{E d}$ is the design shear load and $M_{E d l}, M_{E d 0}, M_{E d x}$ are the design moment loads at the corresponding locations. As $M_{E d x}$ can only be calculated with a known $l_{e}$, an initial steel section is chosen based upon the preliminary design loads $V_{E d}, M_{E d l}$ and $M_{E d 0}$. Based on this, the $l_{e}$ is calculated from Step 3. The final choice of the section and its embedment length is done based on a trial and error relationship provisional to the next steps.

Step 3: Calculating the embedment length inside the concrete: As shown in Fig. 1b, calculating from the face of RC wall, the equilibrium equations for concrete resistance mechanism for Configuration 1, can be written as shown in Eq. (5) and (6).

$$
\begin{aligned}
& f_{b} a b_{e f f}+V_{E d}=f_{b} c b_{e f f} \\
& M_{E d 0}-f_{b} a b_{e f f}\left(l_{e}-\frac{a}{2}\right)+f_{b} c b_{e f f} \frac{c}{2}=0
\end{aligned}
$$

where, $f_{b}$ is the bearing strength of concrete and is equal to $0.85 f_{c k}$ as proposed in the previous studies [7-9], $f_{c k}$ is the characteristic compressive strength of the concrete, $b_{\text {eff }}$ is the effective flange width of the embedded profile and is taken as $b_{\text {profile }}\left(t / b_{\text {profile }}\right)^{0.66}$ as proposed in the foretold researches [7-9], $t$ is the wall thickness and $b_{\text {profile }}$ is the flange width of the embedded profile initially chosen to start the design based upon $V_{E d}, M_{E d l}$ and $M_{E d 0}, a$ and $c$ are as indicated in Fig. 1b. It can be easily observed that there are actually three unknowns with two equilibrium equations. However, we can replace $c$ with $\left(0.55 l_{e}\right)$ as determined and verified from the FE parametric studies for such connections. So, based on the equilibrium equations, the newly developed relationship to calculate the required embedment length can be written as in Eq. (7),

$$
l_{e}=\frac{1}{f_{b} b_{e f f}}\left[0.9 V_{E d}+\sqrt{4 M_{E d 0} f_{b} b_{e f f}+2.85 V_{E d}^{2}}\right]
$$

After a suitable $l_{e}$ is chosen, the embedded profile is determined accordingly with respect to $b_{\text {eff }}$ of the initially chosen section and $M_{E d x}$ through a trial and error method. For Configuration 2, as shown in Fig. $2 b$ for the passing through connection, the equilibrium equations can be written as in Eq. (8) and (9):

$$
\begin{aligned}
& f_{b} a b_{\text {profile }}+V_{E d}=f_{b} c b_{\text {profile }}+V_{E d} \\
& 2 M_{E d 0}+V_{E d} l_{w} \\
& -f_{b} a b_{\text {profile }}\left(l_{w}-\frac{a}{2}\right)+f_{b} c b_{\text {profile }} \frac{c}{2}=0
\end{aligned}
$$

where, $l_{w}$ is the length of wall. However, as $l_{e}$ is known in this case and can be taken as $l_{n} / 2$ (accounting for symmetry), the embedded profile can be chosen based upon $l_{w}$ and $M_{E d x}$. Thus, $a$ and $c$ are calculated from the equilibrium equations and checked to be smaller than $0.2 l_{w}$ to ensure safety in the concrete. The choice of $c$ and $a$; and $b_{\text {profile }}$ instead of $b_{\text {eff }}$ for Configuration 2 are also validated through the parametric study.

Step 4: Finalizing the embedded profile section: The embedded profile section is chosen with respect to all the design loads, as shown in Eq. 10 and 11 below, to ensure that the embedded section does not yield prior to yielding of the shear link.

$$
\begin{aligned}
& V_{p l . R d, p r o f i l e}>V_{E d} \\
& M_{p l . R d, p r o f i l e}>M_{E d x}>M_{E d 0}>M_{E d 1}
\end{aligned}
$$

Where, the design shear and moment resistances are $V_{p l, R d, \text { profile }}=\frac{A_{v} f_{y}}{\gamma_{M 0} \sqrt{3}}, M_{p l, R d, p r o f i l e}=\frac{W_{p l} f_{y}}{\gamma_{M 0}}$ respectively to base the calculation and verification on the upper characteristic value of the yield strength for the considered steel grade. $A_{v}$ and $W_{p l}$ denotes the shear area and plastic section modulus of the embedded profile.

Step 5: Design of Beam Splice connection: The beam splice connections are designed according to the Eurocode 3 [13] guidelines for maximum and minimum end distance or bolt spacing against the $M_{E d l}$ and $V_{E d}$ design loads. 


\section{Description of Case Studies}

In order to search for an adequate couple of vertical bearing stresses and their distribution through the embedded profile, a detailed parametric study was carried out with 10 different embedment lengths $(200 \mathrm{~mm}, 250 \mathrm{~mm}$, $300 \mathrm{~mm}, 350 \mathrm{~mm}, 375 \mathrm{~mm}, 400 \mathrm{~mm}, 450 \mathrm{~mm}$, $500 \mathrm{~mm}, 550 \mathrm{~mm}$, and $600 \mathrm{~mm}$ ) and 4 different $\mathrm{M}_{\mathrm{Ed} 0} / \mathrm{V}_{\mathrm{Ed}}$ ratios $(0.5 \mathrm{~m}$ to $2 \mathrm{~m})$ for Configuration 1. However, for Configuration 2, as the $l_{e}$ is constant, the distribution was checked with the foretold $\mathrm{M}_{\mathrm{Ed} 0} / \mathrm{V}_{\mathrm{Ed}}$ ratios (defined as $X_{F E}$ in Eq. 13). Both connection configurations were studied in a view to accommodate a seismic link assumed to be located at the ground story section of the 6 storied structure with a coupling ratio $40 \%$ as studied in a previous research [11]. The length of the wall is $2.1 \mathrm{~m}$ and its width is $0.36 \mathrm{~m}$. The designed and verified wall cross-section is illustrated in Fig. 4. Concrete is taken as class $\mathrm{C} 30 / 37$ and reinforcements are taken to be B450C following the EC2 guidelines [14]. Reinforcements are designed according to the DCM rules stated in EC8, Clause 5.4.3.4 [12] for ductile walls. The link section was obtained from the previous study [11] and has an overall depth of $200 \mathrm{~mm}$, flange width of $100 \mathrm{~mm}$, flange thickness of $17 \mathrm{~mm}$, web thickness of $5.6 \mathrm{~mm}$. The link length was varied from $400 \mathrm{~mm}$ to $1900 \mathrm{~mm}$ to produce the 4 different $\mathrm{M}_{\mathrm{Ed} 0} / \mathrm{V}_{\mathrm{Ed}}$ ratios with the link acting as a lever arm. The offset length, $l_{0}$, is considered as $100 \mathrm{~mm}$ for all cases. A HEB 220 section was considered as the embedded profile for Configuration 1 and HEM 220 for Configuration 2 based on the design outcomes. Stiffeners are provided, at a distance of $l_{e} / 6$ from the face of the RC wall and the embedded end of the profile to support the flanges against local buckling during the activation of the bearing resistances. 2 plates with dimensions of $(300 \mathrm{~mm} \times 300 \mathrm{~mm} 25 \mathrm{~mm})$ are used in all cases for the splice connection. Steel grade S355 (nominal yield stress, $f_{y}=355$ $\mathrm{MPa}$ ) is adopted for both the coupling links and the embedded profiles, stiffeners as well as the beam splice connection plates.

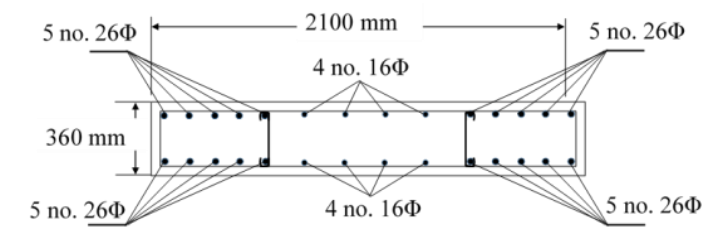

Fig. 4. Reinforcement detailing for RC wall of the 6 storied HCW system [11]

After the parametric study, two final FE models were designed according to the previously discussed procedure. Although both the models fulfilled the desired design objective, they are not discussed in this particular study, to avoid any distraction and solely focus on the development and refinement of the design procedure presented in section 2 .

\section{Modelling Approach}

The different configurations are modelled and analysed through nonlinear analyses by means of full 3D model resorting to solid elements implemented in the finite element software DIANA 10.1 [15]. Nonlinear plasticity is introduced in the RC wall through an elasticperfectly plastic stress strain relationship for the concrete considering the design compressive strength. However, the shear links, beam splice connection as well as the embedded profiles are kept elastic isotropic for the parametric study to solely focus on the stress behaviour inside the concrete along the embedment region to the maximum possible limit. Afterwards, an elasticperfectly plastic material for the steel reinforcements, and nominal plastic stress-strain material properties for the steel S355 was considered to analyze the design models. A perfect bond was assumed at the interface of the embedded steel and concrete to avoid unnecessary complications and heavy models. Fig. 5 shows the models used for the finite element analysis.

(a)

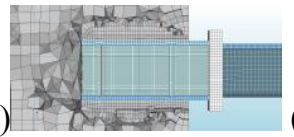

Fig. 5. FEMs used in DIANA:

(a) Configuration 1 (b) Configuration 2

\section{Parametric Study for Configuration 1}

An adequate couple of vertical bearing stresses and their distribution creates the primary foundation for such a connection design. Firstly, in reference to Fig. 1b, the $c$ was assumed to be $l_{e} / 3$ as proposed by the previous researches [7-9] to solve Eq. (5) and (6) and determine the required $l_{e}$. However, the resulting designs were found to be rather conservative in terms of safety. The bearing resistance of the $\mathrm{RC}$ wall in the FE models was much greater than what was anticipated from the design procedure. Thus, a parametric study was done with 10 different embedment lengths and 4 different $\mathrm{M}_{\mathrm{Ed} 0} / \mathrm{V}_{\mathrm{Ed}}$ 
ratios via multiple pushover analyses. A further equation was introduced as Eq. (12).

$$
M_{E d 0}=X V_{E d}
$$

where $X$ is the theoretical moment to shear ratio and is slightly different from the ratio considered in the FE models as shown in Eq. 13.

$$
X=X_{F E} \gamma_{o v}
$$

where, $X_{F E}$ is the actual $\mathrm{M}_{\mathrm{Ed} /} / \mathrm{V}_{\mathrm{Ed}}$ ratio working on the FE models. For example, in the FE models, if a vertical load is applied at the end point of the shear link and $\left(l_{\text {link }}+l_{0}\right)$ is taken as $0.5 \mathrm{~m}$ to create a $\mathrm{M}_{\mathrm{Edo}} / \mathrm{V}_{\mathrm{Ed}}$ ratio $\left(X_{F E}\right)$ of 0.5 ; it corresponds to a ratio of 0.625 for the theoretical formulas $(X)$ due to the different safety factors used in Eq. (1) and (3).Then, assuming $c$ equals $l_{e} / 3$, the maximum moment and shear resisted by the RC wall was calculated by solving Eq. (5), (6) and (12). These theoretical results were compared with maximum capacities of the corresponding FE models obtained from the pushover curves. The safety margin defining the ratio of $\mathrm{FE}$ results to theoretical results are plotted in Fig. 6 for flexural resistance of the RC wall. Fig. 7 shows the calculated $a$ values as a fraction of $l_{e}$. Due to resemblance, the shear safeties are not shown. $\mathrm{M} / \mathrm{V}$ in all the plots denotes the $\mathrm{M}_{\mathrm{Ed} 0} / \mathrm{V}_{\mathrm{Ed}}$ ratios used for the $\mathrm{FE}$ simulations $\left(X_{F E}\right)$.

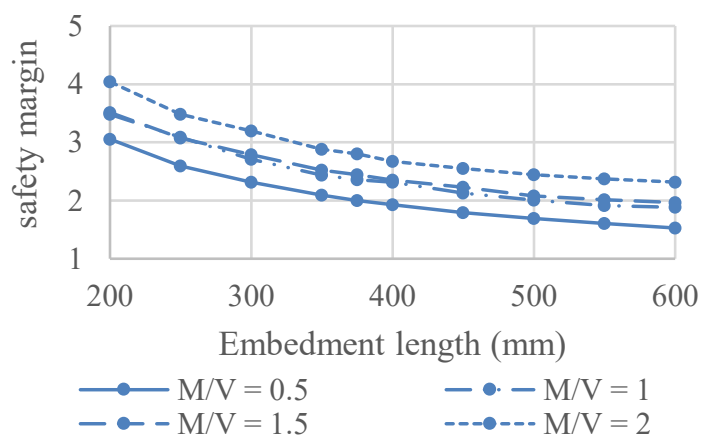

Fig. 6. Moment safety assuming $c=l_{e} / 3$

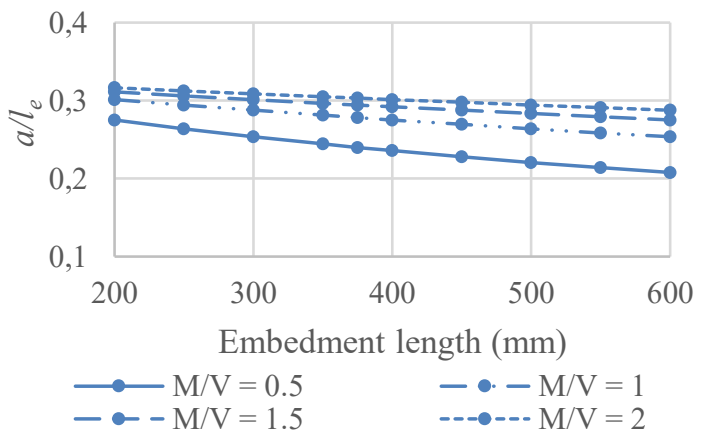

Fig. 7. Variation in $a$ assuming $c=l_{e} / 3$
As seen in Fig. 6 and 7, the conservative nature due to the initial assumptions was clearly noticed as the theoretical moment resistance and $a$ values were calculated to be significantly lower than the simulation results, which are presented later. Therefore, a thorough parametric study was done varying the $c$ (as a fraction of $l_{e}$ ) for each combination of embedment length and $X_{F E}$. It was interestingly observed that, with a $c$ value approximately equal to $0.55 l_{e}$, the lowest safety margin or highest accuracy was achieved for moment, shear resistances and the $a$ values, in all cases, compared to the FE models, as shown in Fig. 8. Due to qualitative similarity, only the moment safeties for $500 \mathrm{~mm}$ embedment length are plotted for varying $\mathrm{M}_{\mathrm{Ed} 0} / \mathrm{V}_{\mathrm{Ed}}$ ratios.

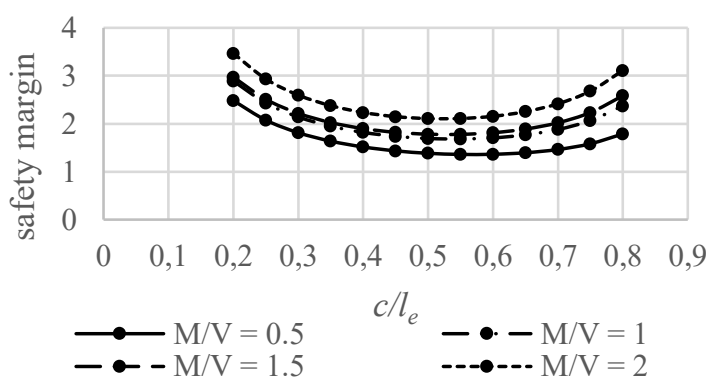

Fig. 8. Moment safety for varying $c / l_{e}$

Therefore, this $c$ value $\left(=0.55 l_{e}\right)$ as well as the resulting $a$ values for different embedment lengths and $\mathrm{M}_{\mathrm{Ed} 0} / \mathrm{V}_{\mathrm{Ed}}$ ratios were checked with the FE nonlinear simulations and was validated successfully as shown in the later part of this section. The safety margin thus decreased, resulting in a higher accuracy for the theoretical design procedure compared to the FE results. In Fig. 9 and 10 respectively, the upgraded results for moment safety and $a$ values are compared with the previous calculations to provide evidence towards this inference.

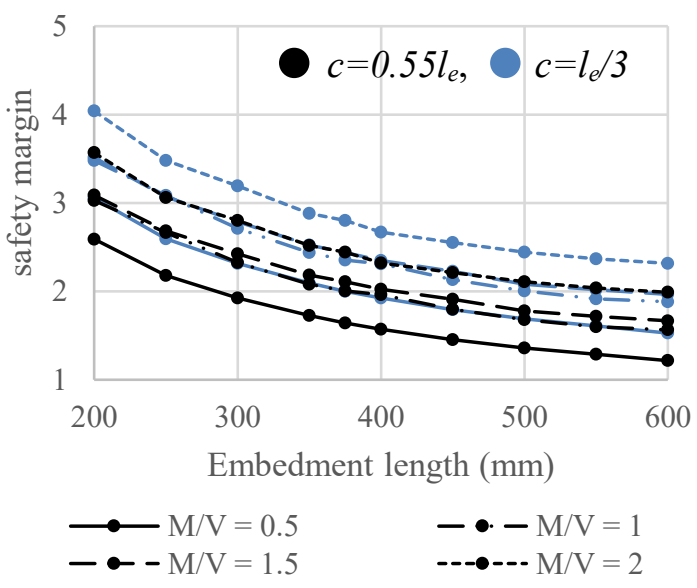

Fig. 9. Moment safety comparison 


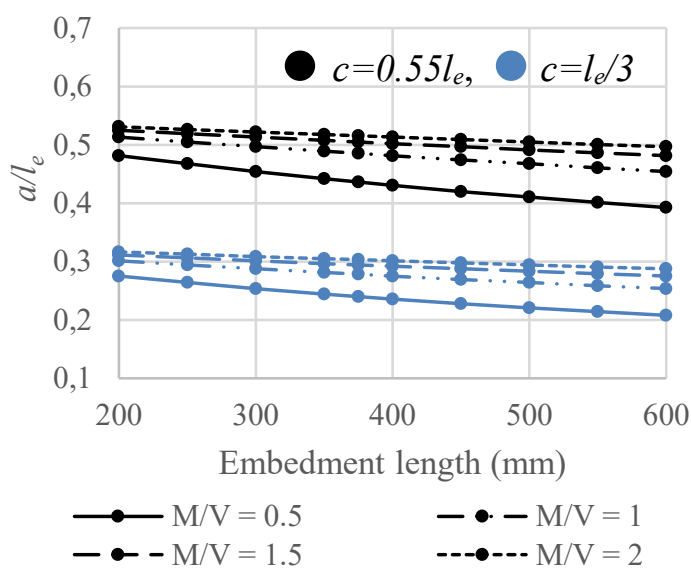

Fig. 10. Comparison for $a$ values

These improved results were thus checked using the FE models. The stress distribution below the bottom flange and above the top flange of the embedded profile, at the maximum registered moment obtained from each pushover analysis, are plotted to bring clarity regarding $c$ and $a$. Fig. 11 represents the principal compressive stresses below the bottom flange corresponding to validation of $c$, whereas, Fig. 12 shows the same above the top flange relevant to $a$.
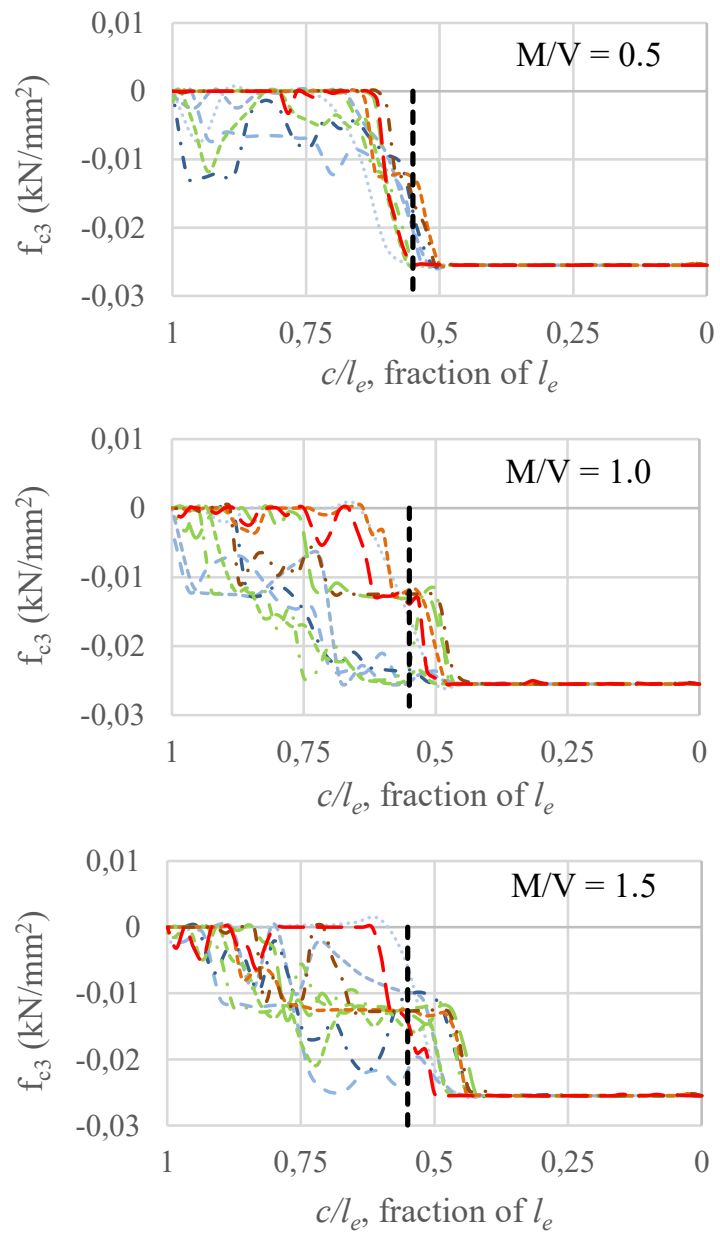

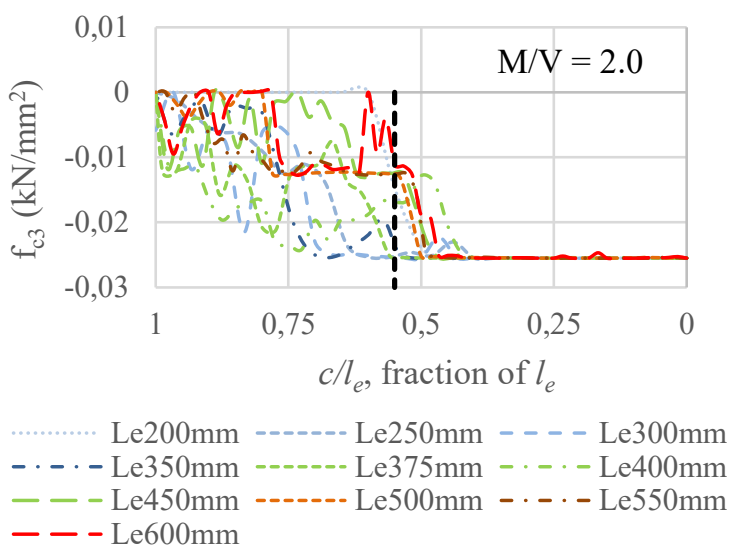

Fig. 11. Principal compressive stress distribution below the bottom flange to validate $c$
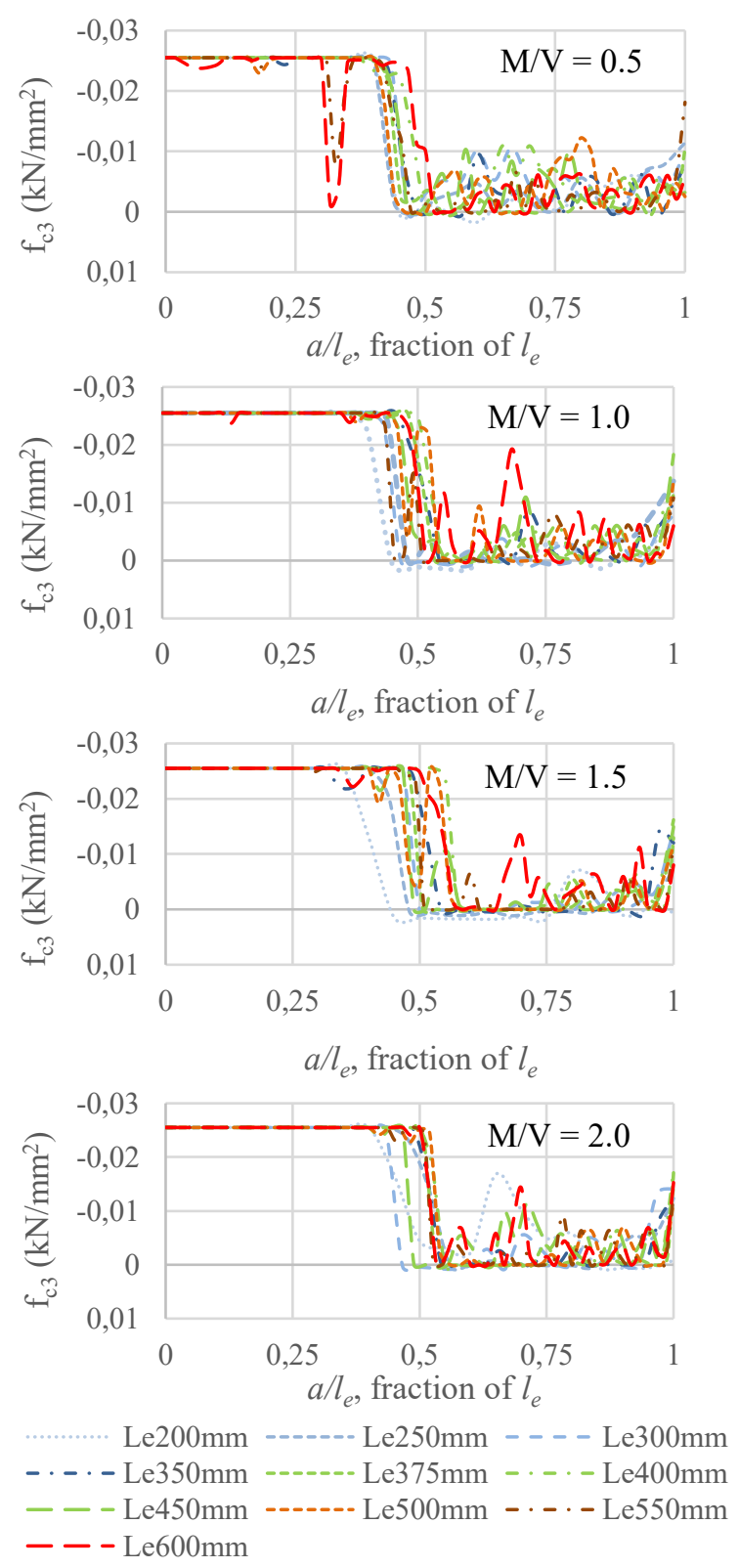

Fig. 12. Principal compressive stress distribution above the top flange to validate $a$ 
Some evidence suggested that the principal compressive stresses were not oriented in a perfectly vertical manner due to presence of small shear forces along the embedment length. Nevertheless, these shear forces originate from the perfect bond assumed in the steel-concrete interface and can reasonably be neglected as a sliding behaviour is certainly expected in a real case scenario. Therefore, the plotted principal stresses were chosen to validate the design procedure. In Fig. 11, $c$ is calculated starting from the face of the $\mathrm{RC}$ wall to designate its relation with $l_{e}$, while, in Fig. 12, $a$ is calculated from the embedment end of the profile to characterize the fractional relationship. From Fig. 11, the principal compressive stresses related to $c$ are observed to be distributed till a fractional value of approximately 0.55 for all the combinations of embedment length and $\mathrm{M}_{\mathrm{Ed} 0} / \mathrm{V}_{\mathrm{Ed}}$ ratio verifying the design assumption. Furthermore, comparing Fig. 10 and 12, the $a$ values were also seen to agree closely with the revised theoretical calculations, i.e. assuming $c$ $=0.55 l_{e}$. Although the stress distributions are not uniform till $0.55 l_{e}$, presence of arbitrary bearing stresses beyond that length makes the proposed $c$ value an optimum yet safe choice for such connection design procedure.

\section{Parametric Study for Configuration 2}

As shown in Fig. 2b, also for Configuration 2, a couple of vertical bearing stresses resist the overturning moment. Due to lack of previous investigations concerning such passing through configuration, $c$ was primarily assumed to be $l_{e} / 3$ (where $l_{e}$ is calculated as half the length of the wall, $l_{w}$ ), and $b_{\text {eff }}$ was also considered alike Configuration 1 as acquired from the existing literature. However, these primary assumptions were investigated through a detailed parametric study with FE models similar to the previous section. Although $c=l_{e} / 3$ ( or $l_{w} / 6$ ) was found to be a bit conservative, $b_{\text {eff }}$ seemed to be slightly optimistic as the FE models suggested $b_{\text {profile }}$ to be a more reliable and safe choice instead. As the embedment length is fixed in this configuration, a parametric study was done only with 4 different $X_{F E}$ ratios. Therefore, w.r.t the FE models, the previous assumptions were modified considering $b_{\text {profile }}$ instead of $b_{\text {eff }}$ and $c=0.2 l_{w}$. Then, the resisting moment and shear capacity of the RC wall was calculated by solving Eq. (8), (9) and (12), and were thus compared with the corresponding FE models. The safety margins

for flexural capacity of the RC wall were obtained to be 1.02, 1.08, 1.21 and 1.24 for $X_{F E}$ ratios $0.5 \mathrm{~m}, 1 \mathrm{~m}, 1.5 \mathrm{~m}$ and $2 \mathrm{~m}$ respectively. The principal compressive stresses (blue denotes max compression) below the bottom flange and above the top flange are shown in Fig. 13 for $X_{F E}$ $0.5 \mathrm{~m}$, to clarify the choice of $b_{\text {profile }}$ instead of $b_{\text {eff }}$. The corresponding $a$ and $c$ values were validated with the stress distribution obtained from the FE simulation results below the bottom flange and above the top flange of the embedded profile. Fig. 14 represents the principal compressive stresses below the bottom flange corresponding to validation of $c$ as a fraction of $l_{w}$, whereas, Fig. 15 shows the same above the top flange for $a$.

(a)

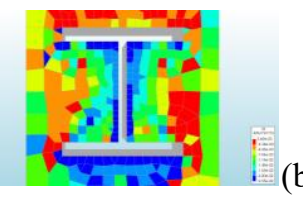

(b)

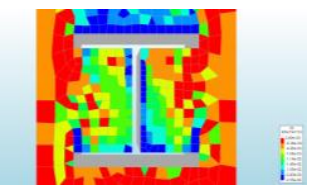

Fig. 13. Principal compressive stresses (a) below bottom flange (b) above top flange

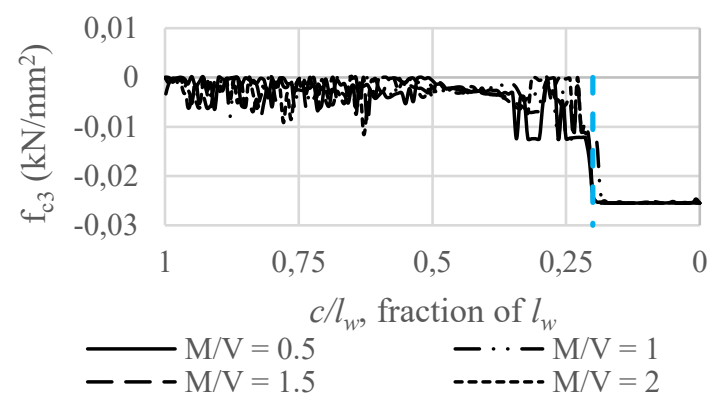

Fig. 14. Principal compressive stress distribution below the bottom flange to validate $c$

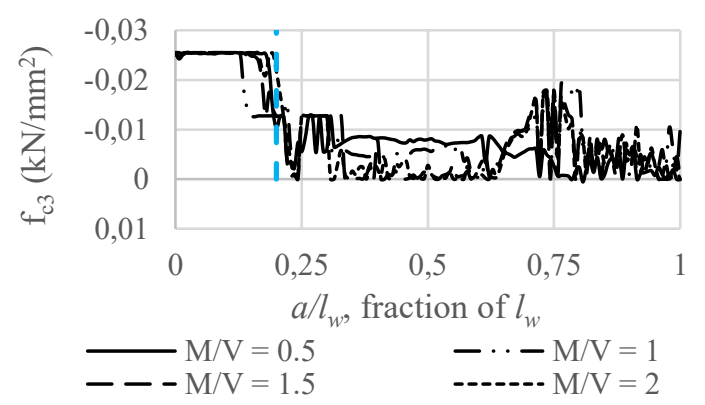

Fig. 15. Principal compressive stress distribution above the top flange to validate $a$

From Fig. 14 and 15, the compressive stresses related to $c$ and $a$ are observed to be distributed till a fractional value of approximately $0.2 l_{w}$ for all the $\mathrm{M}_{\mathrm{Ed} 0} / \mathrm{V}_{\mathrm{Ed}}$ ratios. This validates the design assumptions of a simpler rectangular stress distribution with $c=0.2 l_{w}$. Presence of arbitrary bearing stresses beyond that length explains the residual safety margins. 


\section{Conclusions}

The seismic design and behavior of a steel embedded connection was investigated with the purpose of improving in detail a recently proposed innovative hybrid coupled shear wall structure. The design procedure was developed based upon equilibrium equations and Eurocode guidelines and was implemented for two different possible configurations. Several nonlinear parametric analyses were carried out in order to develop and verify the proposed design method and finally refine it to utilize its complete potential.

The design procedure proposed in this study can be reliably used to compute the required embedment lengths and profiles according to the demand. Even though full accuracy could not be reached compared to the FE results due to a rather complicated behaviour in the concrete, the choices made in this method such as the rectangular stress distribution, $c=0.55 l_{e}$ (for Configuration 1) and $c=0.2 l_{w}$ (for Configuration 2 ), offers a simple and safe, yet, optimized solution to design such composite connections. The residual safety margins occur due to the presence of some arbitrary stresses in the FE models beyond the assumed theoretical $c$ values. Although, consideration of $b_{\text {eff }}$ strongly agreed with Configuration1, it was deemed slightly optimistic for Configuration 2. The safety margins increased with increase in the $\mathrm{M}_{\mathrm{Ed} 0} / \mathrm{V}_{\mathrm{Ed}}$ ratio for both configurations. However, they showed an inverse relationship with the embedment lengths for a particular $\mathrm{M}_{\mathrm{Ed} /} / \mathrm{V}_{\mathrm{Ed}}$ ratio.

Nevertheless, the final design outcomes for both configurations were later studied based on a pushover analysis and was seen to successfully meet the targeted design objective, i.e. steel links yielding in shear prior to minimal damage in the RC wall and the embedded connection. However, these results will be shown in a following article to solely dedicate this study towards explaining the detailed development of this design procedure. In the future, the FE models will also be checked with respect to cyclic loads.

\section{References}

[1] Paulay T. Coupling beams of reinforced concrete shear walls. ASCE Journal of Structural Engineering 1971; 97(3): 843-862.
[2] Paulay T, Santhakumar AR. Ductile behaviour of coupled shear walls. ASCE Journal of Structural Engineering 1976; 102(1): 93-108.

[3] El-Tawil S, Kuenzli CM, Hassan M. Pushover of Hybrid Coupled Walls, Part I: Design and Modelling. ASCE Journal of Structural Engineering 2002a; 128(10): 1272-1281.

[4] El-Tawil S, Kuenzli CM. Pushover of Hybrid Coupled Walls, Part II: Analysis and Behavior. ASCE Journal of Structural Engineering 2002b; 128(10): 1282-1289.

[5] Zona A, Degee H, Leoni G, Dall'Asta A. Ductile design of innovative steel and concrete hybrid coupled walls. Journal of Constructional Steel Research 2016; 117: 204-213.

[6] Marcakis K, and Mitchell D. Precast concrete connections with embedded steel members. Journal Prestressed Concrete Institute 1980; 25(4): 86-116.

[7] Mattock AH, Gaafar GH. Strength of embedded steel sections as brackets. ACI Journal 1982, 79(9): 83-93.

[8] Raths CH. Embedded structural steel connections. PCI Committee on Connection Details, PCI Manual on Design of Connections for Precast Prestressed Concrete 1973, Prestressed Concrete Institute, Chicago, 104112.

[9] Kent DC, Park R. Flexural members with confined concrete. Journal of the Structural Division, ASCE 1971, 97(ST7): 1969-1990.

[10] Minami K. Beam to Column stress transfer in composite structures; composite and mixed construction. ASCE 1985, In: Roeder C, editor. New York.

[11]Das R, Zona A, Vandoren B, Degee $\mathrm{H}$. Performance evaluation of an innovative HCW system with shear dissipative links. CE/papers 1, No. 2 \& 3, EUROSTEEL 2017, Copenhagen, Denmark, September 13-15.

[12]European Committee for Standardization, Eurocode 8: Design of Structures for Earthquake Resistance - Part 1: General Rules, Seismic Actions and Rules for Buildings. EN 1998-1, December 2004.

[13]European Committee for Standardization, Eurocode 3: Design of Steel Structures - Part 1-1: General Rules and Rules for Buildings. EN 1993-1-1, May 2005.

[14]European Committee for Standardization, Eurocode 2: Design of Concrete Structures Part 1-1: General Rules and Rules for Buildings. EN 1992-1-1, December 2004.

[15]DIANA User's Manual, DIANA Release 10.1, March, 2017. 